\title{
A study on hoof abnormalities among working don- keys presented to veterinary clinics in and around Mekelle, Ethiopia
}

\author{
Tewelde Fisahaye ${ }^{1}$, Reta Tesfaye ${ }^{2^{k}}$ and Hagos Yihdego ${ }^{3}$ \\ ${ }^{1}$ Tigray Regional State, Western Tigray Zone, Keta-Humera District \\ ${ }^{2}$ Addis Ababa University, College of Veterinary Medicine and Agriculture, SPANA Ethiopia \\ project \\ ${ }^{3}$ Donkey Health and Welfare Tigray project, Mekelle \\ ${ }^{*}$ Corresponding author email : reta.tesfaye@gmail.com
}

\begin{abstract}
A study was conducted from November 2013 to May 2014 in three selected sites in and around Mekelle town, Ethiopia. The objectives of the study were to estimate the prevalence of hoof abnormalities in working donkeys and to assess associated risk factors with its occurrence. Severity of lameness was also assessed in relation to types of the abnormalities. A total of 415 working donkeys were randomly selected from those donkeys that visited the stationary and mobile clinics in the study area. History taking and thorough clinical examination were used as a tool to conduct the study. The overall prevalence of hoof abnormality was found to be $14.7 \%$. Trauma was found to be the major $(52.5 \%)$ type of hoof problem, followed by hoof over growth (19.7\%), hoof crack (14.8\%) and thrush (13.1\%).The occurrence of hoof abnormality was significantly associated with body condition scoring $(p<0.05)$ in which it was higher in donkeys with poor body condition. Other factors such as site, age, stable floor type and working time were not significantly associated $\left(x^{2}=2.016\right.$, $p>0.05$ ) with the occurrence of the hoof abnormality. Hoof abnormalities identified had resulted in Grade I to IV lameness. Grade 4 lameness was mainly (94.7\%) caused by trauma. Grade 3 lameness was caused by trauma $(72.2 \%)$ and thrush (27.8\%). Grade 2 was caused by hoof crack (50.0\%), thrush (33.3\%) and hoof over growth (16.7\%). Grade 1 lameness was due to hoof overgrowth (61.1\%) and hoof crack (33.3\%) and trauma (5.6\%). Generally, it was identified that hoof abnormalities due to trauma, thrush, hoof over growth and hoof crack were a health problem of working donkeys in the study area. Community awareness enhancement on prevention and management of hoof abnormalities is recommended.
\end{abstract}

Ethiop. Vet. J., 2018, 22 (1), 111-120 
Keywords: Clinical examination; Hoof abnormalities; Lameness; Prevalence; Risk factors.

\section{Introduction}

The hoof is the horny covering over the distal end of the third digit. It has a complex three dimensional structure and consists of a horny capsule. It is made up of the wall and bars, the sole, the frog and the bulbs of the heels. The hoof capsule thus forms a coherent, resilient boot, such that distortion of any particular part affects the remainder (Hepworth et al., 2004; Davies and Philip, 2007; Frandson et al., 2009). The wall makes up the largest part of the hoof capsule and it has a major function in weight bearing. The bars are the parts of the wall that have turned inward from the heels to surround the frog. The sole is also composed of tubular and inter tubular horn and is produced from tissue overlying the base of the pedal bone. The frog is a readily recognized V-shaped structure with its narrowest part pointing forward. The bulbs of the heels are the softer, rounded regions of horn immediately above the heels of the hoof wall (Pillineret al.,2004; Svendsen, 2008).

Hooves are subjected to several injuries when animals are either out in the pasture or while they are being ridden or driven. Most commonly encountered equine hoof problems among others are thrush, hoof crack, equine canker and white line disease (Christopher et al., 2000; Booth and White, 2007). Thrush is the term commonly used to describe a pododermititis of the frog caused by Fusobacterium necrophorum. Hoof cracks are fractures of hoof capsule that are named after their location. Equine canker is a hypertrophic, moist dermatitis of the frog and the bulbs of the heel. White line disease is most commonly an incidental finding at the time of routine trimming and shoeing. It appears as a localized separation of the white line and further exploration with a probe or shoeing nail often reveals undermining of hoof wall (Christine, 2004; MacDonald et al.,2006; Booth and White, 2007). Mechanical trauma due to stone and punctures with sharp objects and over grown hooves are all common types of hoof wall problems (Christopher et al., 2000: Booth and White, 2007).

Hoof lesions can cause a wide spectrum of clinical presentations that range from very subtle losses of performance to sever lameness (Kempson, 1990; Keegan and Dyson, 2003). Although an animal with hoof problem may be able 
to function, chances are that optimal animal production and performance can be reduced depending up on the severity of the problem (Hepworth et al., 2004). The hoof is an extremely important structure in animal body (Reilly, 1995). Disorders of the hoof have important health and welfare implication in donkeys. Hoof abnormalities and the resultant lameness can signal suffering and leads to increased energy expenditure, reducing ability to work and income for donkey-owners (Keegan and Dyson, 2003; Iqbal et al., 2006). Generally, hoof is essential for locomotion and overall wellbeing of donkeys. Majority of lameness in equine arises from hoof problem (Baxter, 2011). The distribution of hoof abnormalities is thought to vary depending on different risk factors. The situation in Ethiopia has not been well addressed in general and there has been no study conducted in and around Mekelle particularly on hoof abnormalities to the authors' best knowledge. Therefore, the objectives of this study were to estimate the prevalence of hoof abnormalities and assess risk factors associated with its occurrence in working donkeys and identify the types of abnormalities and its impact in causing lameness.

\section{Materials and methods}

\section{Study area}

The study was conducted in and around Mekelle city namely, Mekelle, Adigudom and Quha. Mekelle is the capital city of Tigray Regional State and it is located in the northern part of Ethiopia at $13^{\circ} 29^{\prime}$ North latitude and $39^{\circ} 28^{\prime}$ East longitude with an altitude of 2,000 to 2,270 meters above sea level. The mean annual rainfall ranges from $450 \mathrm{~mm}$ to $600 \mathrm{~mm}$. The mean minimum temperature ranges between $10.2^{\circ} \mathrm{C}$ and $12.6^{\circ} \mathrm{C}$, while, the mean maximum temperature varies between $22.3^{\circ} \mathrm{C}$ and $26.7^{\circ} \mathrm{C}$ (Niguse, 2015). The total population of horses, donkeys and mules were 2,412, 69, 2179 and 4690 respectively in Tigray region (CSA, 2013). Of this, Mekelle city possess about 1,200 horses, 1,792 donkeys and 223 mules (MOUA, 2013).

\section{Study population}

Randomly selected 415 working donkeys that were presented to the donkey sanctuary clinics to receive veterinary service such as deworming and treatment against various diseases in Mekelle, Adigudom and Quha during the study period were included in this study. These donkeys play major role in the area as a pack animal. All were local breed. 


\section{Sample size determination and sampling technique}

The sample size required was determined by the formula stated in Thrusfield (2007) based on 50\% expected prevalence, $95 \%$ confidence level and $5 \%$ of absolute precision.

$\mathrm{N}=1.96^{2} \mathrm{P}_{\text {exp }}\left(1-\mathrm{P}_{\text {exp }}\right) / \mathrm{d}^{2}$

Where $\mathrm{N}=$ required sample size

$\mathrm{P}$ exp= expected prevalence

$\mathrm{d}=$ desired precision

$\mathrm{Z}=1.96$ for $95 \%$ confidence interval.

$\mathrm{n}=1.96^{2} 0.5(1-0.5) / 0.05^{2}=3.84 \times 0.25 / 0.0025=384$

Therefore to study the prevalence of hoof abnormalities and associated risk factors in working donkey in and around Mekelle city, a minimum of 384 working donkeys are required. Owners who presented their donkeys seeking various clinical services were registered at the beginning. They all were informed about the purpose of the study and about the sampling procedure. After their willingness was confirmed each donkey was identified using systematic random sampling with a target of seven to ten donkeys per clinic visit. Accordingly, a total of 415 donkeys were included from the three sites.

\section{Study design}

A study was conducted from November 2013 to May 2014 on selected working donkeys that were presented to the donkey sanctuary clinics in and around Mekelle town, Ethiopia. A check list was used to collect data on causes, management practices such as stable floor and risk factors associated with hoof abnormalities such as site, sex, frequency of use of donkeys, and body condition score. Body condition scoring was based on the guideline given by Svendsen (2008). Thorough clinical examination was used as a tool to identify hoof abnormalities.

\section{Clinical examination}

Physical clinical examination was undertaken according to Baxter (2011). Visual examination, examination by manipulation and palpation were used in the diagnosis of the foot abnormalities. The foot was inspected for any hoof over growth, signs of cracks, discharge, injury and poor conformation and 
palpated for signs of increased heat and pain detection. Hoof tester, hoof pick and hoof knife were used during the examination. The donkeys were examined at rest and in motion.

Careful examination of donkeys at rest was conducted by first observing animals at distance followed by close visualization from front, sides and behind to assess symmetry of hoof problem, conformation, the condition and alteration of posture, weight shifting and pointing followed by close observation of each limb.At close examination, each foot was examined with the leg in the weightbearing position. These include: palpation of the palmar digital vein, artery, and nerve bundle, examination of the heel bulb area, viewing and palpation of the coronet, palpation and careful examination of the entire hoof wall for any defect. This was followed by examination of the foot in the non-weight- bearing position which involves examination of the frog, the bars, the sole and the white line.

Examination of donkeys in motion was conducted to identify the limbs involved and the degree of lameness and coordination in movement. Each selected donkeys were examined while it was walking and trotting. The degree of lameness was categorized in to four according to Baxter(2011); grade 1, grade 2, grade 3 , and grade 4 depending on level of severity of lameness in increasing order.

\section{Data management and analysis}

The data collected from the owners and results of clinical examination was entered in to the Microsoft excel spread sheet and it was analyzed using SPSS version 20 statistical software. Descriptive statistics were used to quantify the hoof abnormalities and Chi-square $\left(\mathrm{X}^{2}\right)$ was used to determine the association of the abnormalities with the risk factors. Prevalence of hoof abnormalities was estimated as proportion of donkeys with hoof abnormalities out of the total donkeys examined. In all calculations, the confidence interval was set at $95 \%$ and statistically significant difference was considered at $p<0.05$.

\section{Results}

A total of 415 working donkeys consisting of 369 males and 46 females were included in this study. The overall prevalence of hoof abnormalities among donkeys that visited veterinary clinics during the study period was $14.7 \%(\mathrm{n}=61)$. The majority $(43,70.5 \%)$ of the hoof abnormalities was observed on forelimbs 
as compared to the hind limbs. The hoof problems identified include; injury/ trauma, hoof over growth, hoof crack and thrush as depicted in Table 1.

Table 1. Type and proportion of hoof abnormalities among working donkeys in and around Mekelle town $(n=415)$

\begin{tabular}{lcccc}
\hline $\begin{array}{l}\text { Type of } \\
\text { abnormality }\end{array}$ & $\begin{array}{l}\text { No of donkeys } \\
\text { with hoof } \\
\text { abnormality }\end{array}$ & percent & Chi-square & (p-value) \\
\hline Injury or trauma & 32 & 7.7 & 4.15 & 0.000 \\
Hoof over growth & 12 & 2.9 & \\
Hoof crack & 9 & 2.2 & \\
Thrush & 8 & 1.9 & \\
\hline
\end{tabular}

Statistically significant difference in the occurrence of the hoof abnormalities was observed only among the body condition scores and stable floor whereas the difference in other factors such as site, sex and frequency of use of donkeys were not significantly associated with the occurrence of hoof abnormalities as indicated in Table 2.

With regard to the frequencyof use of donkeys, the majority $(194,46.7 \%)$ of the owners replied that it is difficult for them to tell the exact frequency of use of their donkeys as they use some times intensively and other time less frequently. One hundred sixty (38.6\%) owners replied that they use their donkeys on daily basis. The remaining $37(8.9 \%)$ and 24 (5.8\%) owners use their donkey one to six days in a week and one to three days in a month, respectively.

Hoof abnormalities identified had caused different degrees of lameness. Grade 1 lameness was mainly due to hoof overgrowth and hoof crack. Grade 2 was associated with hoof crack, thrush and hoof over growth. Grade 3 and 4 lameness was caused by trauma and thrush. The detail is described in Table 3. 
Table 2. Association of hoof abnormalities in relation to site, sex, body condition score floor type and frequency of use of donkeys

\begin{tabular}{|c|c|c|c|c|}
\hline Risk factors & $\begin{array}{l}\text { Total No } \\
\text { examined }\end{array}$ & $\begin{array}{l}\text { Abnormalities } \\
\text { No(\%) }\end{array}$ & $\begin{array}{l}\text { Chi- } \\
\text { square }\end{array}$ & p-value \\
\hline \multicolumn{5}{|l|}{ Site } \\
\hline Quiha & 168 & $23(13.7 \%)$ & 2.02 & 0.365 \\
\hline Adi-gudom & 180 & $31(17.2 \%)$ & & \\
\hline Mekelle & 67 & $7(10.5 \%)$ & & \\
\hline \multicolumn{5}{|l|}{ Sex } \\
\hline Male & 369 & $57(15.4 \%)$ & 0.28 & 0.159 \\
\hline Female & 46 & $4(8.7 \%)$ & & \\
\hline \multicolumn{5}{|l|}{ Body condition } \\
\hline Poor & 98 & $32(32.7 \%)$ & 33.36 & $(0.000)$ \\
\hline Moderate & 187 & $19(10.2 \%)$ & & \\
\hline Good & 130 & $10(7.7 \%)$ & & \\
\hline \multicolumn{5}{|l|}{ Stable } \\
\hline Earthen floor & 286 & $49(17.1 \%)$ & 4.35 & 0.037 \\
\hline Concrete floor & 129 & $12(9.3 \%)$ & & \\
\hline \multicolumn{5}{|l|}{ Frequency of use } \\
\hline Unknown & 194 & $32(16.5 \%)$ & 1.28 & 0.735 \\
\hline Daily & 160 & $20(12.5 \%)$ & & \\
\hline 1-6 days in a week & 37 & $6(16.2 \%)$ & & \\
\hline $\begin{array}{l}\text { 1-3 days in a } \\
\text { month }\end{array}$ & 24 & $3(12.5 \%)$ & & \\
\hline
\end{tabular}

Table 3. Severity of lameness in relation to types of hoof abnormalities

\begin{tabular}{lcccc}
\hline \multirow{2}{*}{$\begin{array}{l}\text { Types of } \\
\text { abnormalities }\end{array}$} & \multicolumn{4}{l}{ Grade of lameness } \\
\cline { 2 - 5 } & Grade 1 & Grade 2 & Grade 3 & Grade 4 \\
\cline { 2 - 5 } & No. (\%) & No. (\%) & No. (\%) & No. (\%) \\
\hline Trauma & $1(5.6)$ & - & $13(72.2)$ & $18(94.7)$ \\
Thrush & - & $2(33.3)$ & $5(27.8)$ & $1(5.3)$ \\
Hoof over growth & $11(61.1)$ & $1(16.7)$ & - & - \\
Hoof crack & $6(33.3)$ & $3(50.0)$ & - & - \\
Total & $18(100)$ & $6(100)$ & $18(100)$ & $19(100)$ \\
\hline
\end{tabular}




\section{Discussion}

In the present study, the overall prevalence of hoof abnormalities in working donkeys was $15 \%$.This result is comparable with $16.3 \%$ report from Hawassa, Ethiopia by Assefa et al (2017). More than half of these abnormalities were injury or trauma due to different factors. This was followed by hoof over growth, hoof crack and trush. Donkeys travel long distance under rugged terrain environment. This might have contributed to the occurrence of high level of injury compared to other types of abnormalities such as hoof crack, hoof overgrowth and thrush. The presence of the second more common abnormality, hoof over growth, might indicate lack of regular proper hoof trimming practices as hoof over growth in most of the cases is not considered as a major problem by the donkey owners. The low proportion of trush in this study might be due to the absence of conducive stable environment for the survival and multiplication of the causative organism.

In the current study, the prevalence of hoof abnormalities was found higher $(70.5 \%)$ in the fore limbs compared to the hind limbs (29.5\%). In contrary to this, Assefa et al (2017) and Bolbol and Saleh (1987) reported higher prevalence in the hind limbs. This might be due to the difference in use and the owners' attitude toward their donkeys. Assefa et al (2017) indicated beating on hind limb as a cause of lameness in donkeys used for pulling carts which is not the case in the current study animals, where donkeys were used as pack animals.

The present study found that, hoof abnormalities were significantly higher in donkeys with poor body condition as compared to those with moderate body condition and good body condition. This result is in agreement with other studies (Broster et al., 2009; Burn et al., 2010). This might be due to the fact that donkeys with hoof abnormality are unable or not comfortable to move freely and graze or search for feed. This might have resulted in reduced feed intake and the subsequent poor body condition or possibly it might be due to increased energy expenditure on locomotion.

In this study, the proportion of donkeys with more severe (Grade III and Grade IV) form of lameness due to the hoof abnormalities was high (60\%). This implies the compromise of health and welfare of donkeys due to the hoof abnormalities is significant. 


\section{Conclusion}

This work presents hoof abnormalities as one of the health and welfare problems in and around Mekelle town, Ethiopia. The hoof abnormalities identified were injury or trauma, hoof over growth, hoof crack and trush. These abnormalities resulted in Grade I to Grade IV lameness. Hoof abnormality in working donkeys is one of the major health and welfare concern contributing to reduced work performance. Therefore, community education and awareness enhancement about health and welfare of donkeys including regular inspection of the hoof of donkeys and immediate visit of veterinary clinics should be practiced to alleviate hoof problems. In addition, further study on hoof abnormalities should be conducted in different working groups of donkeys.

\section{Acknowledgements}

We gratefully acknowledge Donkey Health and Welfare Tigray project and all its staff members for their cooperation and technical support in accomplishing this research.

\section{Conflict of interest}

The authors declare that there is no conflict of interest.

\section{References}

Assefa, G., Abera, B., Nur, A., Lemma, D., Keno, L., Eticha, E., Chali, G. and Hussen, M., 2017.The major cause of lameness and associated risk factors in working donkey in and around Hawassa town, Ethiopia. J. Vet. Sci. Techn., 8, 427.

Baxter, M. G., 2011. Examination for lameness. In: Baxter, M. G (Ed.), Adams and Stashak's Lameness in Horses, $6^{\text {th }}$ edition. Blackwell Publishing, Ltd, Pp. 109-112.

Bolbol, A. E., and Saleh, A. S., 1987.Survey on equine hoof affection in Upper Egypt. J. Egypt Vet. Med. Assoc., 47, 545-553.

Booth and White, 2007. Pathologic conditions of the external hoof capsule. In: Floyd, A. E. and Mansmann, A. R. (Ed.), Equine Podiatry. Saunders Company Ltd, Pp. 225- 252 .

Broster, C. E., Burn, C. C., Barr, A. R. S. and Whay, H. R., 2009. The range and prevalence of pathological abnormalities associated with lameness in working horses from developing countries. Equine Vet. J., 41, 474-481. 
Burn, C. C., Dennison, T. L. and Whay, H. R., 2010. Environmental and demographic risk factors for poor welfare in working horses, donkeys, and mules in developing countries. Vet. J., 186, 385-392.

Christine, A. R., 2004. Disorders of the skin. In: Reed, M. S., Bayly, M.W. and Sellon, C.D. (Ed.), Equine Internal Medicine. Elsevier, USA, Pp. 667-720.

Christopher, R., David, R. H. and Revenbenj, R., 2000. Manual of equine practices, $2^{\text {nd }}$ ed., Saunders Company Ltd.

Davies, M. S. H. and Philip, C., 2007. Gross anatomy of the equine digit. In: Floyd, A. E. and Mansmann, A. R. (Ed.), Equine Podiatry. Saunders Company Ltd, Pp. 1-56.

Frandson, D. R., Wilke, W. L. and Fails, D. A., 2009. Anatomy and Physiology of farm animals, $7^{\text {th }}$ ed., Wiley-Blackwell.

Hepworth, K., Neary, M. and Keyon, S., 2004. Hoof anatomy, care and management in livestock. Purdue University Cooperative Extension Service, West Lafayette. www.ces.purdue.edu/new.

Iqbal, A., Raza, S. H., Ahsan-Ullah and Riaz, M., 2006. Developments and research in equine husbandry and welfare: some issues in Pakistan. In: Proceedings, the $5^{\text {th }}$ International Colloquium on Working Equines the Future for Working Equines. The Donkey Sanctuary, 5 November 2006, Sidmouth, UK. .

Keegan, K., and Dyson, J. S, 2003. Clinical investigation of foot pain. In: Rose, W. M. and Dyson, J. S. (Ed.), Diagnosis and Management of Lameness in the Horse. Elsevier Science USA, Pp. 242-249.

Kempson, S. A., 1990. Ultra structural observation on the response of equine hoof defects to dietary supplementation with ferrier's formula. Vet. Record, 127, 494-498.

MacDonald, M. H., Kannegieter, N., Peroni, J. F. and Merfy, W. M. E., 2006.The musculoskeletal system.In:Higgins, J. A. and Snyder, R. J. (Ed.), The Equine Manual, $2^{\text {nd }}$ ed.Elsevier Limited, Pp. 964-1010.

MOUA, 2005. Regional animal health research program strategy document Mekelle office of urban agriculture (MOUA), Mekelle, Ethiopia

Niguse, A., 2015 Precipitation and Temperature Trend Analysis in Mekelle City,Northern Ethiopia, the Case of Illala Meteorological Station. J. Env. Earth Sci., 5(19),46-52

Pilliner, S., Elmhurst, S. and Davies, Z. 2004.The horse in motion.Blackwell Science Ltd, Oxford, UK.

Reilly, J.D., 1995. No hoof no horse. Equine Vet. J., 27, 166-168.

Svendsen, E.D., 2008. The professional hand book of the donkey, $4^{\text {th }}$ edition, Whittet Books Ltd, Wiltshire, UK.

Thrusfield, M., 2007.Veterinary epidemiology, $3^{\text {rd }}$ ed., Blackwell Science Ltd, Oxford, UK. 